\title{
The Children's Playgrounds in Apartments and Terrace Housing Areas: Places of Leisure or Failure?
}

\author{
Ahmad Sid Hijaz Md. Saaid ${ }^{1} \&$ Ahmad Sanusi Hassan ${ }^{2}$ \\ ${ }^{1}$ Architecture Program, Department of Civil Engineering, Ungku Omar Polytechnic, Malaysia \\ ${ }^{2}$ School of Housing, Building \& Planning, Universiti Sains Malaysia, Malaysia \\ Correspondence: Ahmad Sanusi Hassan, School of Housing, Building and Planning, Universiti Sains Malaysia, \\ 11800 USM, Penang, Malaysia. Tel: 60-19-506-8260. E-mail: sanusi@usm.my; sanusi.usm@gmail.com
}

Received: July 13, 2014 Accepted: September 14, 2014 Online Published: October 30, 2014

doi:10.5539/ass.v10n22p128 URL: http://dx.doi.org/10.5539/ass.v10n22p128

\begin{abstract}
Colourful playgrounds are made for the young children. But, aren't they being provided for leisure or failure? This paper has conducted an assessment on the children's playgrounds that located in the housing areas of apartments and terraces. Such study is ubiquitous in the developed world, however, in Malaysia this topic is neglected, the children's playgrounds are presumed to be in good conditions because they were assessed at a distance. An observational survey was conducted on 57 children's playgrounds in the playing areas of apartments and terrace housings scattered in several cities of West Peninsular Malaysia. The safety checklist and playground grading forms which were used as the main survey instruments was modified based on the original checklist from the United States Consumer Product Safety Commission and the grading system was adapted from the United States National Program for Playground Safety. The safety evaluations stressed on four elements; the surfacing materials, drainage, general hazards and equipment maintenance. The result, most of the playgrounds were struggled to comply with the safety checklists. Significant problems and faulty issues on equipment were composed in the form of graphical images to enhance the discussions. Half of the sampling population managed to get the minimum $\mathrm{C}$ grades and only to be rated as the average playgrounds. If Malaysia's playgrounds are prioritized not on safety and neglecting their equipment maintenance, the number of failure playgrounds will surely increase and so does the playground accidents.
\end{abstract}

Graphical Abstract:
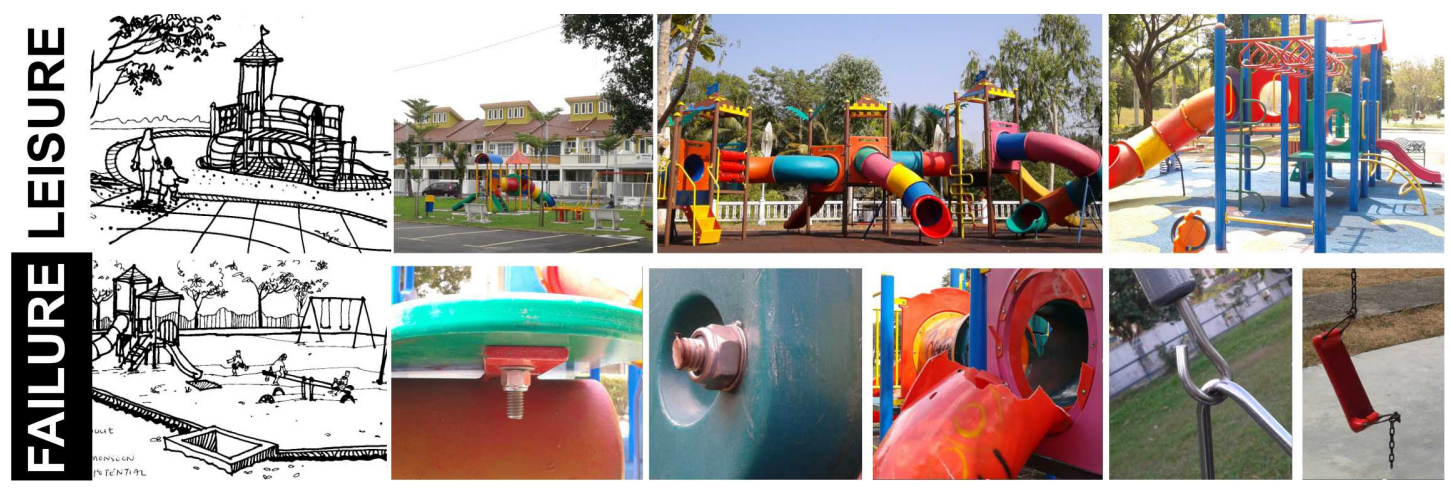

Keywords: playground safety, surfacing materials, drainage, general hazards, equipment maintenance

\section{Introduction}

\subsection{The Proving Grounds of Children's Playgrounds}

A children's playground is a place in the open air where playground equipment is installed and intended to be used by children to play, to develop competence and a positive sense of self (Beugels, 1993; Zeece \& Graul, 1993; Gordon, 1981). According to Deconinck (2009), there is no such thing as absolute safety. Hence, the most challenging task for any playground designer is to eliminate all inadmissible risks, but permits exploration on the playground to the fullest joy and excitement experiences (Minuzzo, Rowan, \& Young, 2009; Bachvarov et al., 
2008; Moore et al., 2006).

Children are used to play in their acquisition of knowledge (Piaget, 1962) and they play because it comes naturally (Shier, 1984). For them, play is the best tool to learn their life discovery (Stoecklin, 2000). Outdoor socialization is important for children to get their life's lessons such as respect, cooperation, communication and leadership, while developing strength and agility as well as a multitude of new physical skills (Kutska, 2007; Hurlock, 1978). Being regarded as a tool for children to see the real world (Smoyer-Tomic et al., 2004), a playground is the place of what it means to be a part of the children's growth (Sutterby \&Thornton, 2005). For the purpose of psychological justifications, the best answer is to provide the children with the appropriate playgrounds (Mani et al., 2012; Amouzegar et al., 2009).

Presently, the playground issues have drawn an interdisciplinary attentions and debates among the scholars. Regardless of their scopes and interests, every article under this region, has never failed to compliment the essentiality of the playground for the children. The playground design evoked very fast. Having a multi-shape or an integrated unit of a composite-play structure (CPS) is becoming a popular trend to many playgrounds nowadays (United States Consumer Product Safety Commission [CPSC], 2010). The CPS architecturally imposes as a landmark for a gazette recreational area. The surrounding population and locality factors will determine the complexity and the size of the CPS. The playground is essential not only for children, but as an element of leisure for the whole community folks.

The importance of children's playground is undoubted. It is a place of leisure, yet combines with the excitement of the CPS, it becomes even livelier. However, this paper is intended to look at the opposite of the positive parts. Here, the antonym of the leisure is justified as the failure. Meaning, the failure to engage an appropriate safety measures to offer children a protection from playground hazards. Any negligence on the safety will make the children's playground a site of potential accidents. Any efforts to increase free play in the playgrounds must be balanced with concerns for safety (Nixon et al., 2003; Laforest et al., 2001; Mott et al., 1997). Normal wear, amount of usage, environmental factors, and vandalism take a toll on playgrounds and create hazards (White, 2012). Therefore, a comprehensive maintenance plan is essential to ensure that the children's playground is warranted with safety protection.

\subsection{Unsafe Playgrounds}

In 1965, David Aaron through his book Child's Play had questioned the yesterday's playgrounds. He was hoping to see playgrounds were the safest places of happy sanctuary where children were allowed to play freely, but he learnt all that were quite unsafe when a statistic shown that $30 \%$ of childhood accidents occurred in school and municipal playgrounds (Aaron \& Winawer, 1965; Buck, 1988). Ever since, many articles, data and facts have highlighted on accidents, injuries and the importance of safety in playgrounds. Playgrounds are meant for children to play safely (Leung \& Mahadev, 2010) but playgrounds also can cause host to injury, hospitalization and death (Uskun et al., 2008; Bernardo et al., 2001; Bond \& Peck, 1993; Chalmers \& Langley, 1990). More than 213,700 children were treated in the United States emergency departments annually due to injuries sustained in playgrounds (US CPSC, 2010; Howard et al., 2009). $75 \%$ of children were injured by falling, $50 \%$ were equipment related injuries (Morrongiello \& Matheis, 2007; Phelan et al., 2001; Weperan \& Rogmans, 1991) and $45 \%$ of the injuries were severe fractures, internal injuries, concussions, dislocations and amputations (Tinsworth \& McDonald, 2001).

In many other countries, the safety of children's playground is a well-recognized problem (Weperen \& Rogmans, 1991). A study in Wales showed that $90 \%$ of all playground injuries resulting a visit to an emergency department were related to playground equipment (Mott et al., 1994). In New Zealand annually, about 7400 children aged less than 15 years old seek for treatments from the emergency departments (Chalmers et al., 1996). In Ontario, there were more than 8,000 children and 28,500 children all across Canada received hospital treatments because of unintentional injuries sustained while playing on playgrounds (Macpherson et al., 2010; Fiissel, Pattison, \& Howard, 2005). In 1993, the Arizona Department of Health Studies had conducted a study and found that only $72 \%$ of students with reportable injuries were actually taken to the emergency room or to a doctor. This means the actual number of playground injuries should be much higher (Mack, Hudson, \& Thompson, 1997), and they were silently cured without informing their cases to the rightmost authorities.

Playground injuries are common childhood injury in most countries in the developed world (Mitchell et al., 2007; Fiissel, Pattison, \& Howard, 2005; MacKay, 2003; Roseveare et al., 1999). To find the epidemiological statistics and scholarly journals under this topic from abroad countries, were much easier than to find the similar materials from the local source of Malaysia. Nevertheless, there were a lot of newspaper articles concerning this issue as well as estimating for unofficial playground injury statistics that happened in Malaysia. According to the record 
of Epidemiology Accidents Cases in Malaysia, they estimated about 3000 accidents involving children of five to nine years old sustained in Malaysia children's playgrounds in every three months and those cases usually related to playground surfaces (Zain \& Mokhtar, 2012).

\subsection{A Playground that Provides for Leisure or Failure?}

A colourful playground is architecturally appealing and simply acts as a focal point in a neighborhood park (Mani et al., 2012). However, the playground offers a different view of appreciation upon seeing it at a distance or in close proximity. Under a close inspection, one with a good knowledge on playground safety might have found many things not right with the existing playground. Especially, if the playground is an aging one or even the most high-end quality playground cannot withstand a lack of an ongoing and comprehensive maintenance plan (White, 2012). Surely any playground of that kind will offer more failures.

There are plenty of important factors to determine the well-thought-out playground for the children. Even if it is the best one, children cannot be allowed to play freely, the free play activities should only be allowed under adult supervision (Dewi, 2010). After all, the lack of studies pertaining to playground safety and design in Malaysia is the driving force to propel this study to quest for the consequences. What is the utmost importance of the children's playgrounds? Does it the leisure or the failure? Does it the safety or the hazards? Does it good or bad? If all the bad things come to light, what are the local authorities (as the playgrounds' owners) supposed to do next?

\section{Methodology}

An observational survey was employed at a total 57 playgrounds in Putrajaya, Ipoh, Alor Setar and Jitra. Those cities are located in the West Peninsular Malaysia. The majority of samples were playgrounds in the terrace housing areas. Only less than a quarter of the population was playgrounds in apartment residential areas. Though, there were significant measures caused by these two variables, but this research was not intended to differentiate which housing areas could provide for the better playground. Instead, the paper was only focused to find more inputs on the playground safety solutions and to distinguish a clear line between the good and the bad practices?

The sample size and measuring system used in the survey were almost similar to a recent survey formulated by Ersin Uskun in her study on children's playgrounds in Turkey (Uskun et al., 2008). A playground safety form was prepared based on the United States Consumer Product Safety Commission (US CPSC, 2010) checklist and conditional grading was modified based on America's Playgrounds Safety Report Card, National Program for Playground Safety (NPPS, 2006). Twenty six playgrounds were inspected in Ipoh, 10 in Putrajaya, 13 in Alor Setar and 8 in Jitra.

The observation was piloted for about an hour on each session, began in January until March 2014. All records, measures, sketches and pictures were translated into qualitative analyses. In support to the argumentation, several interview sessions were conducted with caregivers and the respective officers from the local authorities. At every visit to the playground sites, no less than ten pictures were taken in order to take notes on the problems and safety issues. The pictures quantitatively served for further analytical studies.

All records and notes of deficiencies on the playground safety forms would be submitted to the respective local authorities for their further actions. The safety form was an improvement checklist for a playground inspector. United States is one of the leading countries where playground inspectors were professionally recognized. They were trained to become Certified Playground Safety Inspectors (CPSI). Their task is to ensure best safety practices and child protection from playground hazards. This study has tried to adapt to the latest models and to bring forward the Malaysian playgrounds with a better standard and safety assessment all together.

\subsection{Assessment Criteria}

As this was an inaugural comparative evaluation of playground safety research in Malaysia, the focus would be weighted on these four criteria:

\subsubsection{Surfacing Materials}

According to the Handbook for Public Playground Safety (HPPS), this checklist was defined as appropriate and inappropriate surfacing materials. Particular attention should be paid to the surfacing details; with materials such as asphalt, cement, concrete frame, grass or bare ground, and of course, these hardened finishes would only make the fall surfacing inappropriate and extremely hazardous. The appropriate surfacing materials could be divided into two categories; loose-fill surfacing and unitary surfacing. The Figure 1 graphical chart gives us a clear picture about this category.

Scholars shared their thoughts and regarded the fall surfacing as the most critical part in the issue of playground 
safety (Allen et al., 2012; Doaa, 2012; Wheway, 2012; Howard et al., 2009; Mott et al., 1997; Beugels, 1993; Bond \& Peck, 1993).

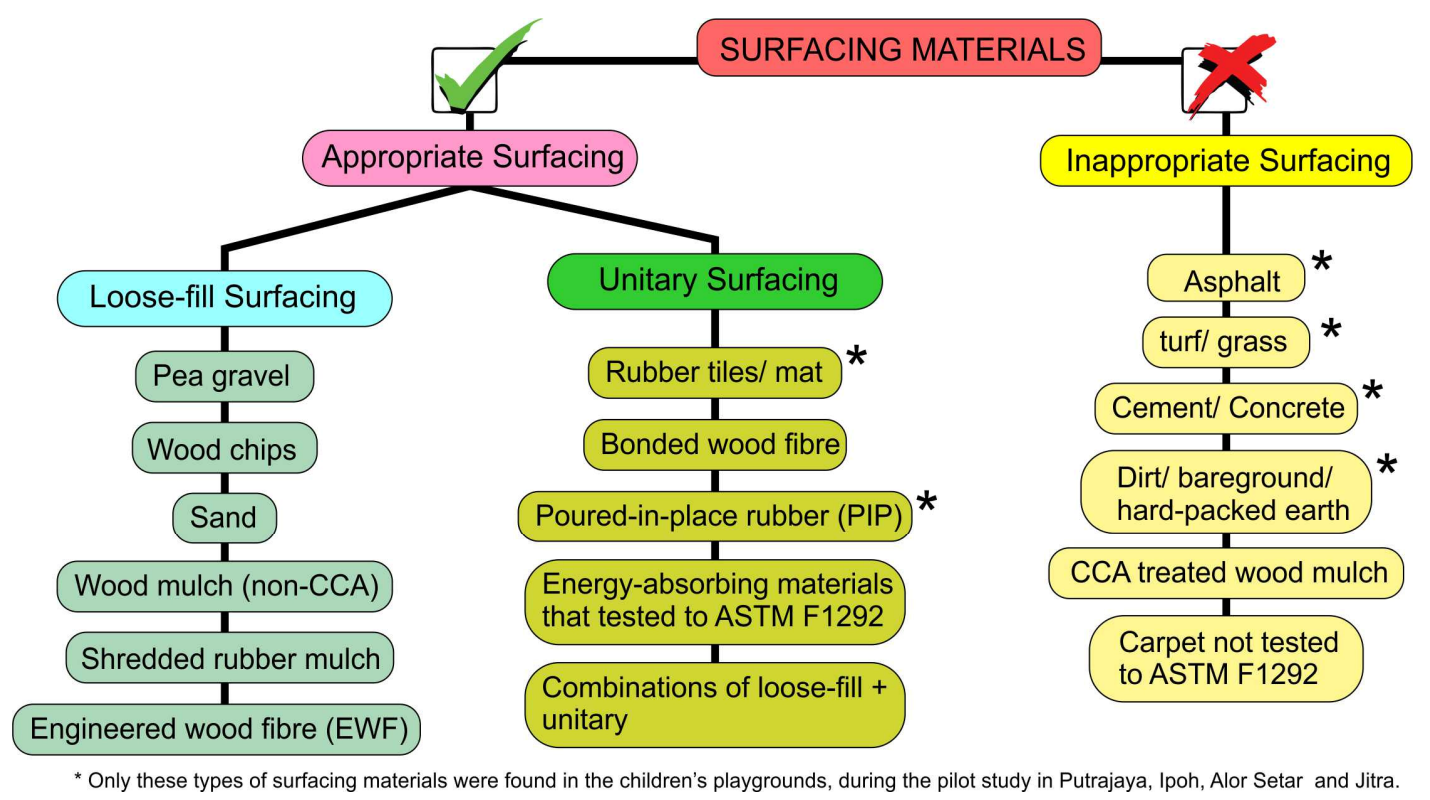

Figure 1. Type of surfacing materials. The asterisk indicates the only surfacing types available in the fields. Further explanation will be discussed in the result and discussion section

\subsubsection{Drainage}

As recommended by the HPPS, the drainage checklist was used to survey all the 57 playgrounds. The result was a bit general, thus, the employment of another method was needed to detail out the finding points on this subtopic.

Good drainage is essential because children's playgrounds are situated in the open areas. Spaces under the swings and at the slide exits were regarded as the most sensitive areas for playgrounds (CPSC, 2010). Nevertheless, a place likes Malaysia, a tropical country which climatically hot, humid and regularly showered with torrential rainfall throughout the year; the implicit effects of the playground equipment were greater than at those sensitive locations.

Case study is a common approach in architectural research. The researchers had chosen to use that approach with all input were gained from several sessions of naturalistic observations focussing on the issue of drainage on the playgrounds. The similar method of case study was also used by Hassan, Emalgalfta and Ku Hassan (2010), in their research on three different resorts in Langkawi Island. The discussions for the checklist of drainage would be done qualitatively with the adaptation of three case studies. The points given in the result's subsections will explain about the seriousness of this problem.

\subsubsection{General Hazards}

All playground provisions were planned and built for the goodness, but the faulty components could be dangerous for children (Mani et al., 2012; Howard et al., 2009). Every scholar on playground safety has never failed to promote extra awareness towards the accident-producing conditions: Sharp edges, protruding bolts and nuts, pinch points, open-ended S-hooks and exposed concrete footings are amongst the hazardous examples that supposed to be eliminated from any playground, anywhere in the world.

Those components will be generally hazardous if they are allowed on the playgrounds with deficiency characteristics. The faulty components are venomous; neglecting their existence is like giving time for them to be patience and slowly waiting to strike their inaugural victim, an unlucky child amongst the innocent children.

The Playground Technical Report, subchapter General Hazards (April 24, 1990) is the most helpful literature under this checklist. The comprehensive 100 page guidance literature discussed every issue of safety and was the basis in the development of the Handbook for Public Playground Safety (US CPSC, 2010); the most notable reference for public children's playgrounds. 


\subsubsection{Durability of Equipment}

The combined factors of weather and outdoor-site have challenged the durability of both playground structures and non-structural equipment. Woods, metals, composite or high-impact plastics are being used as playground materials for decades; however, these components come with a lifespan. Clearly a contradictory, when the play tools are putting outside yet expecting their very best services, long lasting and maintenance-free. Unfortunately, such practices happened in a reality.

Over time, no materials could afford to withstand the extreme natural forces. Durability of equipment is considerably a major factor to determine a good children's playground. Only materials with a good record for outdoor performances should be used (Swartz, 1992).

Materials such as metal, wood, and plastic are common, but each has disadvantages (Bhattacharya et al., 2003; Wade, 2002). Metal can become very hot under direct sunlight and may rust if not maintained. Wood becomes unpopular causing decay of rots and splinters when not regularly treated. Plastic is the most common and has less threat of injuries than woods and metals, but it needs to be provided with routine maintenance. Poor materials would affect the standards and shortened the life of equipment. As a result, those playgrounds would not be warranted with the utmost safety.

\section{Results}

Even though the study has been conducted in four different cities, yet the aim was not to determine which city had prevailed with the utmost playground facilities. The problems of children's playgrounds had been put in the spotlight, hence given out some vivid ideas on the need for more studies pertaining to the topic of playground safety. The study will need to look further for information and discussion could be related to those four mentioned attributes, in which their qualitative analyses will be as follows:

\subsection{Surfacing Problems}

In 1988, a similar survey was conducted on 47 public playgrounds in Boston, USA. All the playground surfaces were inspected inappropriate with plenty of deficiencies and had to be proclaimed unsafe (Bond \& Peck, 1993). However, that study was about a quarter-century ago. With stricter guidelines for playground safety nowadays, their playground surfaces are surely expected to be in much better conditions.
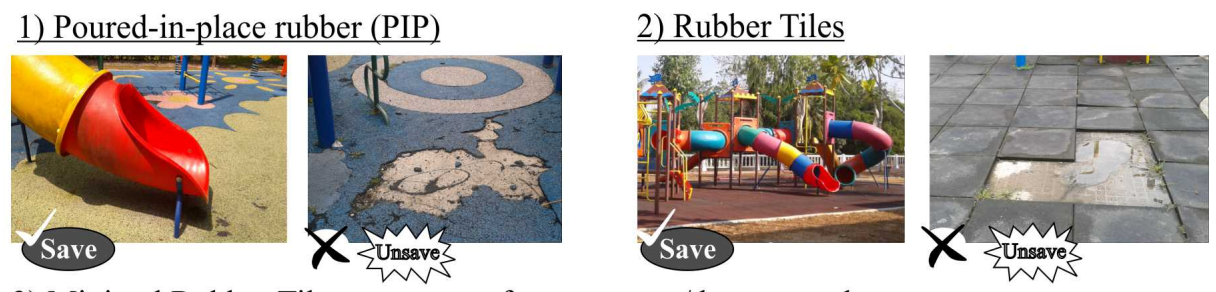

3) Minimal Rubber Tiles + concrete frame + grass/ bareground
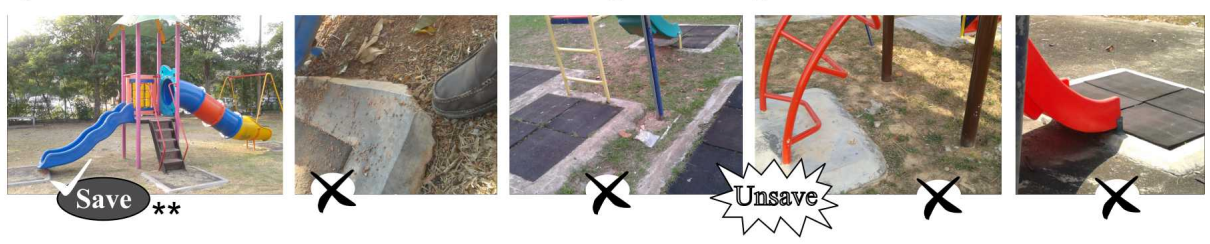

** Saved, but not recommended due to environmental factors (US CPSC, 2010).

Figure 2. The simple comparative analyses on three types of rubber profiles

Meanwhile, on the total of 57 children's playgrounds, in which the field study had taken about two and a half months, the result was not very encouraging. Ten playgrounds (17.5\%) were installed with the state-of-the-art poured-in-place rubber (PIP). Two of them had to be declared unsafe due to their unmaintained conditions. The PIP is a beautiful playground flooring system. With colourful recycle-rubber materials, it can be drawn to attract more children. Playgrounds with this type of surfacing were available in prime recreational areas, capital cities or modern city like Putrajaya.

Twenty-two (38.6\%) playgrounds were using unitary-rubber tiles and $68 \%$ of them were unsafe. Sixteen (28\%) playgrounds had been provided with the non-standard the minimal rubber tiles. Actually, the minimal rubber tile was a combination type, but it should have combined with the loose-fill surfacing (US CPSC, 2010).

The researchers had observed that minimal rubber tiles combined with grass or bare ground surfaces were used 
in lieu of standardized rubber surfacing, which was internationally illegal for playground practice. Though, those surfaces were improvised because of economical budgets, but, such practices had comprised the safety on the playgrounds. From the survey, poorly $94 \%$ of the total playgrounds had to be pronounced unsafe.

A series of graphical analyses are shown in the Figure 2 would help the audience to understand about the comparison conditions of the unitary rubber surfacing.

The last nine (16\%) playgrounds were inspected with the worst inappropriate surfaces. The play areas were only covered with green, bare ground or earth packed surface and cement render; probably waiting for resurfacing works. All of these surfaces were unacceptable and totally unsafe. Overall, 41 (72\%) playgrounds were diagnosed with acute surfacing problems. In other word, the playground surfacing had to be declared unsafe. Remember, the safety survey was only a basic inspection; neither a thorough study of the types of materials nor the surface thickness evaluation was involved at that time. The major deteriorating factor was due to poor maintenance plans.

In terms of safety, the loose-fill surfacing is believed to perform better than the unitary surfacing (Figure1). However, the loose-fill materials require extra care, and for this reason, such materials were unfavoured in Malaysia. Although, the unitary surfacing is everywhere in Malaysia's playgrounds, but, that doesn't mean the material is maintenance-free! In order to maximize play-value and to ensure sustainability; every playground must be provided with a proper maintenance plan.

\subsection{Still Water Problems}

Heavy use areas were the main focus of the survey of the drainage. Attention should be given in two critical locations; the surfaces under the swings and at the slide exits. Generally, the drainage checklist for all playgrounds had achieved a satisfactory result, $75 \%$ of them were rated safe.

Even though drainage was only a small issue compared to other problems, yet it could has given a huge impact unintentionally. Most playgrounds were positioned in the middle of neighborhood open areas. After rainfall, playgrounds without proper drainage will hold water on their surfaces. The water puddles or still-water naturally may not cause any hazard. However, if the still-water is located within the use zone or near to the playground parts, a poor child may trip or fall with his head first onto a hard surface of the playground structure. The injury could be worse if there were sharp edges or protrusions on that particular area.

Naturalistic observations on the playgrounds were conducted in a passive mode. 'Still waters run deep' could be regarded as the process to gain input for thoughts. But, still-water held on the playgrounds must be handled with appropriate measures to avoid any potential accidents.

The following case studies will give clearer pictures on several playgrounds that were affected by drainage problems. Their stories would be related with the synopses given in the Figure $3 \mathrm{~A}, 3 \mathrm{~B}$ and $3 \mathrm{C}$ below.
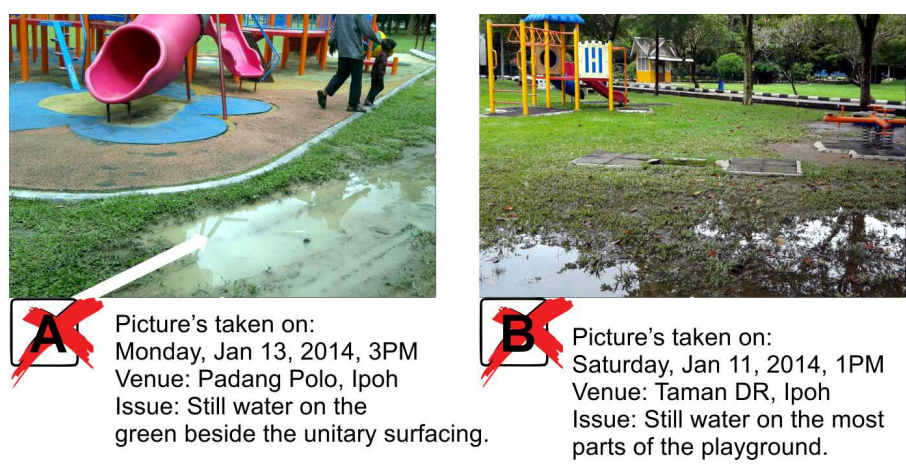

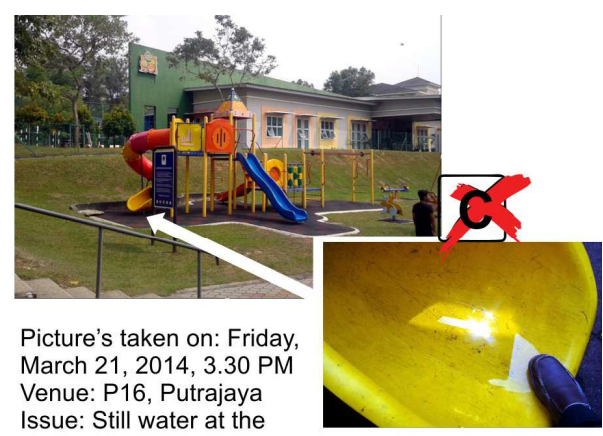

slide exit.

Figure 3. Three examples of naturalistic observations detecting drainage problems

\subsubsection{Case Study A}

As a prime recreational area for the city of Ipoh, the park was surrounded by plenty of shady trees, which made the exterior space naturally pleasant. Neighborhoods of terrace housing areas surrounding the city were normally headed for the park, especially during the weekend to have some recreational activities with their families and friends.

The researcher had visited the site a few times during the research period. This time, the day was hot and humid 
with off-peak activities and not many children were seen at the playground. The composite-play structure (CPS) scale's was the largest in the city. Such design could accommodate between 50-80 playing children at a time. However, the CPS area wasn't really a comfortable place to play. It was a bit off to the center of an open field, which made the CPS left to be exposed to the intense sun. It wasn't just about the harmful effects of sunray or unplayable conditions in a rainy day; the researcher was there where the sun was directly overhead, still several portions of muddy puddles were seen quite close to the main CPS (Figure 3A), probably an evidence of heavy rain several days before. The city council as the playground's owner knew as about this problem; for them muddy puddles were a small matter, but simple hazards were still a hazard and could threaten the children's activities and their safety.

\subsubsection{Case Study B}

A visit was conducted to the playground site hours after a rainstorm wetted the whole area that particular morning (Figure 3B). The weather was very pleasant, but the surfaces were all wet. A few children stormed into the playground area as their parents were watching nearby. The weekend retreat was enjoyable for the children and memorable for their parents as some of them would be going home with their children's clothes dirty and wet. Normally, the kids would enjoy themselves to get dirty, but the playground equipment was not designed for that purpose. A dirty slide would spoil the sliding and the smoothness of the slide surface.

Children's playgrounds in Malaysia were built to be left for the public. Local authorities as the playground owners were normally responsible for major defects. Small deficiencies on playgrounds were normal, as long as they would not threaten the life of any human, no action will be taken. In a large playground park, there were general workers to do all the cleanliness, probably an extra task need to be added to their shoulders; to clean up the wet or dirty playground equipment. The time is ripe for the local authority to train and to employ full-time play workers to efficiently supervise their playground facilities and jointly alert the parents on the safety of their children.

\subsubsection{Case Study C}

The researcher had conducted a trip to Putrajaya; an ultramodern city where their playground facilities were regarded as the finest in Malaysia. Each playground was unique, colourful and outstandingly designed. Whether those playgrounds were designed for apartments or terrace housing areas, most of the playgrounds were built with satisfying landscape environment. Many things could be learned from the tiring one-whole day observations in Putrajaya. Under the issue of drainage, a problem was detected at an apartment's playground in Precinct 16 (not far from the Alamanda; the commercial city centre for Putrajaya). Surprisingly, a puddle of still-water was spotted at the slide exit of the CPS (Figure 3C). Subsequently, any children that going to have fun with the spiral-tunnel slide, would have to wet their trousers. Strangely, that afternoon was a hot and sultry, thus made the researcher did not feel that the water was poured down by anybody. While looking into that, the researcher was sparked with a question: What is actually the effective time of play for an outdoor children's playground?

If it's a rainy day, everything is wet and will take a few days to dry. If it's a dry and sunny day in tropical Malaysia; direct sun can become scorching hot and intense sun exposure on the bare metal playground structures can burn the children's skin. Those conditions will surely limit the time of play. Still-water puddles caused by poor drainage or improper design will threaten the playground and the children's safety. Why not propose an exposed playground with a playground shade? A tensile structure, for instance, will offer some shaded area, gives some protection from the hot sun, the stormy weather and enhances the durability of equipment within the covering area.

\subsection{General Hazards}
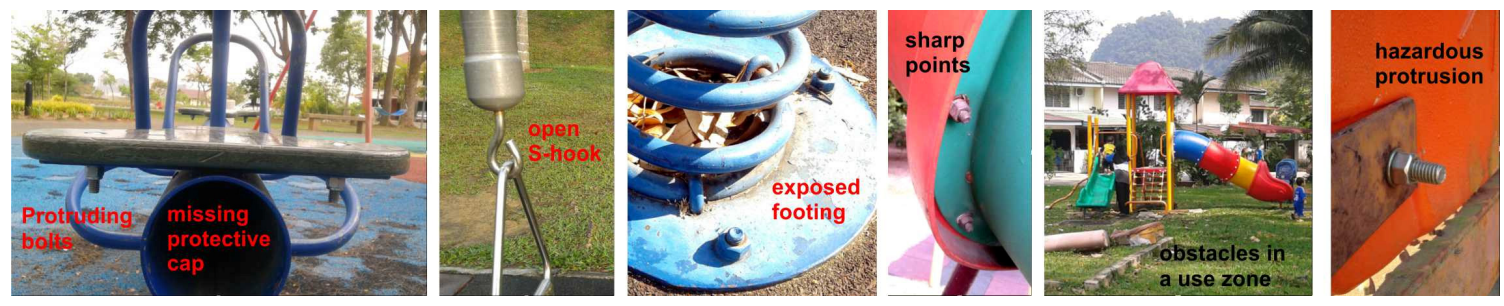

Figure 4. Examples of observations detecting general hazards 
Only $12 \%$ of the entire playgrounds convinced satisfactory in the evaluation of safety for general hazards. These mean, other 50 playgrounds were potentially unsafe and if the study was to look into a bigger scale, the unsafe playgrounds pertaining to general hazards would become far too obvious. Probably, the playgrounds that our kids are playing right now are silently alarming with these issues; yet the equipment is still played by children, and added by the ignorance of their parents' hope that nothing will happen, even though the potential hazards are within a striking distance from biting their children. Equipment was deemed to be the most unsafe (Macpherson et al., 2010). A missing bolt and an end-cap, for example, was thought of being able to be repaired, instead it was retrofitted and left to be an obvious hazardous protrusion.

The problem cases were summarized in the Figure 4. In developed countries, where safety measures were strictly implemented or as followed by the guide from the Handbook for Public Playground Safety (CPSC, 2010), for example, these scenes were surely the taboos. Many factors appeared to have been taken for granted in the issue of general hazards. From observations, the researchers had learnt that the inaccurate practices were accepted in the local business for long. Presumably, the lack of guidance and safety acts were the probabilities that helped this issue to arise, but passively unnoticed by the local authorities until it was proven to cause severe accidents on the playgrounds, only then, the respective bodies would normally start to talk about preventive maintenance. Small defects could be the likelihood for accidents yet a small event of accidents or mishaps sustained by the children were only taken as notions of childhood.

Occasionally, a poor-little child would have fallen off a swing or bruised himself while playing at the neighborhood playground. Such news would be spread out fast within the local community and would be forgotten entirely after a while. The same episode goes to similar cases and at the end, we would not have an inclusive statistics on playground injuries and no actions would be taken by the rightmost authorities.

The observational study in Putrajaya revealed that most playgrounds equipments were proactively maintained by the Putrajaya Corporation (PJC). Kudos for their efforts, all children's playgrounds in Putrajaya were in the best conditions compared to Ipoh, Alor Setar and Jitra. However, if the survey was to use the actual parameter checklists, as recommended by the CPSC (2010); none of the playgrounds would have achieved an A grade. Partly, this was due to the ignorance of general hazards; protrusions of bolts and nuts, for example, were obviously seen under the slide platforms, at the joints of tube slides, under the seat of seesaws etc.

\subsection{Durability of Equipment}
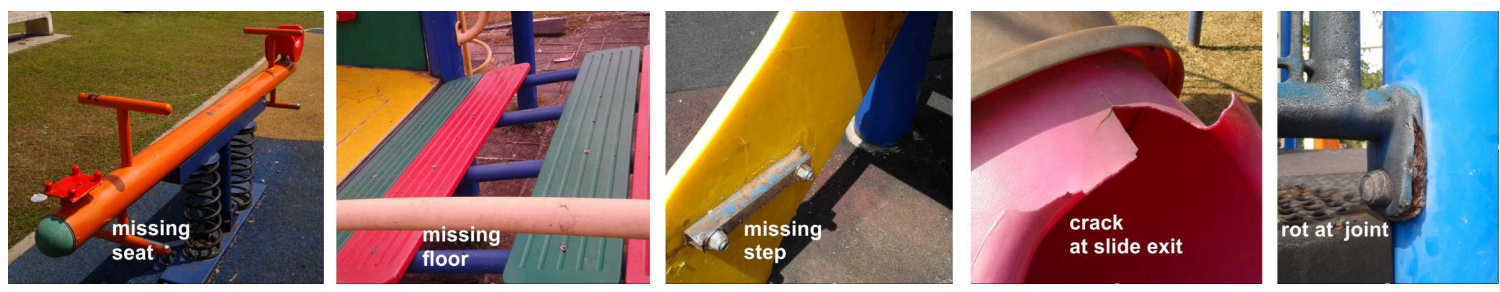

Figure 5. Examples of observations detecting durability problems

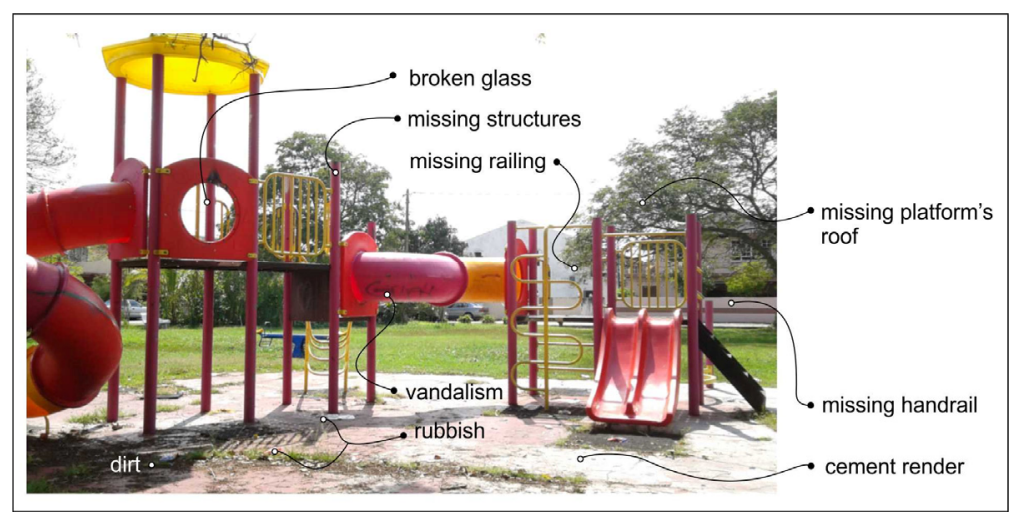

Figure 6. An example of a horrible playground at Selasar Rokam terrace housing area, Ipoh 
The study had recorded 39\% failures under the equipment durability checklist. Durability defects were detected in the form of rust, rot, crack, splinters, and signs of broken and missing components (Figure 5). To ensure good conditions, all playground equipment must be free from any malfunction and deficiency. Only new playgrounds were beautiful, safe and could be offered with adequate safety protections. Aging playgrounds or after three to five years in service; the durability conditions on the playgrounds were shameful. Small defects and deficiencies were mostly left unrepaired. The researchers were afraid that if the worsening playgrounds weren't provided with appropriate maintenance programmes, those playgrounds would become the public nuisance. There were a few horrible playgrounds that should better be demolished because of the intense broken equipment and missing components which had made them unplayable (Figure 6).

\section{Discussion}

This study was a maiden attempt looking through the spectacles of architectural design, upon the children recreational facilities. One of their scopes is the safety issue of children's playgrounds in Malaysia. The major instrument was adapted and modified from the Handbook for Public Playground Safety published by the United States Consumer Product Safety Commission (CPSC, 2010) and America's Playgrounds Safety Report Card endorsed by the National Program for Playground Safety (NPPS, 2006). However, the study couldn't simply use all the recommended checklists, as the children's playgrounds in Malaysia landscape were different from the public playgrounds in the United States. Obviously, playgrounds in Malaysia need to improve on two major attributes; the fall surfacing and the age-appropriate design.

The integrated unit or the composite-play structure (CPS) was contemporary in the modern playgrounds nowadays. In a prime recreational area, a playground park would have consisted more than one CPS on their site. Equipment for younger and older children was grouped together and there was no notification on the equipment about what age group they were produced for. The element of segregation was studied by Uskun et al. (2008). Yearly \& Berlinski (2008) had also proposed the same method, so that the toddlers would be discouraged from using the equipment not designed for them. Besides segregating the CPS functionally based on age-appropriate design, their designs were sometimes very confusing. A child of four years old (and so did his parents) did not know which equipment should his child plays. There was a situation (Figure 7), whereby a group of youth tried their skills on the CPS, because they thought that the 'adventure playground' was meant for them.
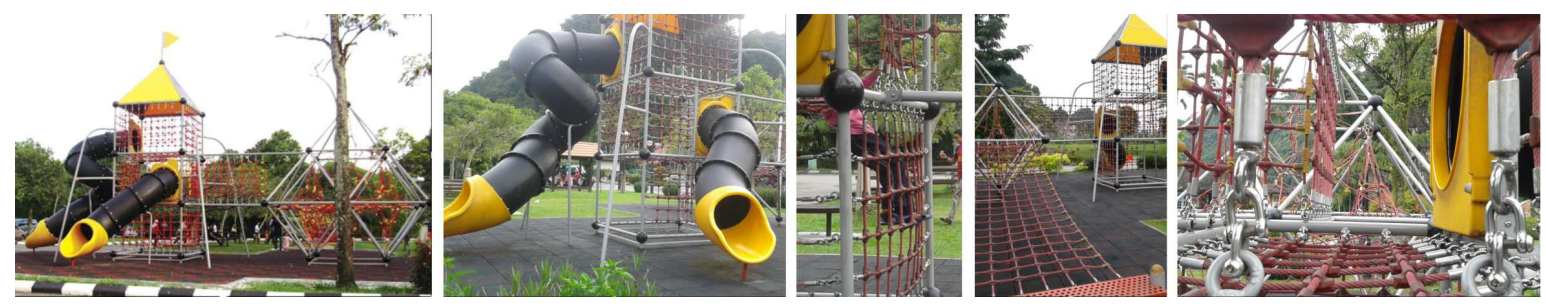

Figure 7. A composite-play structure (CPS) in Gunung Lang, Ipoh that was neither suitable for toddler nor junior children

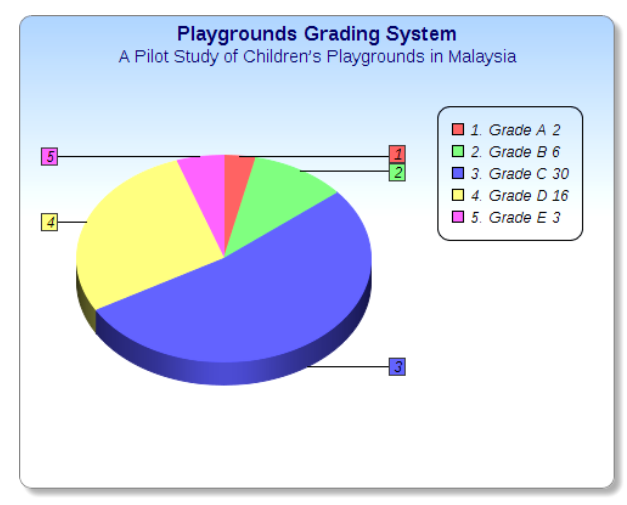

Figure 8A. Playground's grading

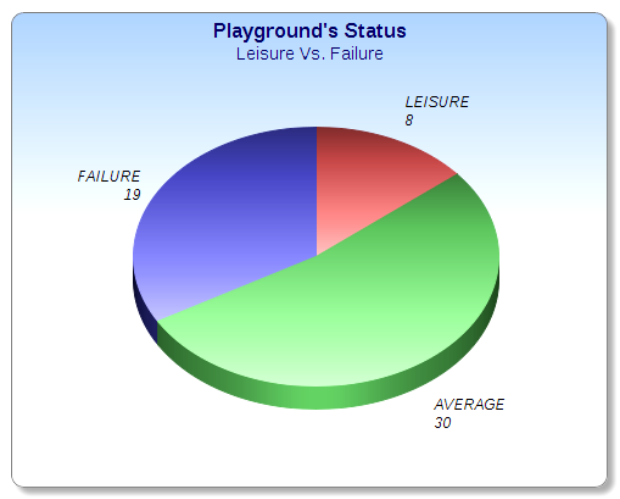

Figure 8B. Playground's status 
This study could not apply the overall grading system that was recommended by the NPPS (2006) due to the non-compliance safety standard and non-standardized equipment. However, after a minor modification on the rubric, the surveyed playgrounds were able to be graded into five classifications (Figure 8A). Astonishingly, only two playgrounds, each were situated in Ipoh and Putrajaya, managed to achieve the excellent "A" grades while another six considered as newly completed playgrounds achieved the "B" grades. These eight playgrounds had answered the research aims at finding the 'leisure' playgrounds that satisfactorily safe and recommended for all children (Figure 8B).

Three of the lowest scored playgrounds fell under the shameful conditions. They were looking like abandoned playgrounds with plenty of deteriorated structures (Figure 7). Those playgrounds could become the danger zones for the public. Presumably, rectification works were in the process, they were left with nothing instead. There should be a notification or at least barricaded by the local authority from causing opportunity of hazards.

Two failures in the category of fall surfacing, general hazards or durability of equipment had brought sixteen playgrounds and classified them as ' $\mathrm{D}$ ' grades. The combination of ' $\mathrm{D}$ and $\mathrm{E}$ ' grades had made up a total of 19 unsuccessful playgrounds. Therefore, almost one-third of the studied playgrounds population was deemed as the 'failure' in playground safety (Figure 8B).

The failure for at least one category of the assessment had brought thirty playgrounds and made them able to get only the ' $\mathrm{C}$ ' grades (Figure 8A), or slightly more than a half of the sampling population has to be rated only as the average playgrounds. Precognition in this study, if there were still without adequate measures of playground maintenance, the number of failure playgrounds will be increased and so does the playground accidents.

\section{Limitation of the Data Analysis}

Potentially, this study could be driven into a much bigger avenue. The supportive quantitative data for example, could be expanded with statistical analyses. However, as to fulfill the nature of architectural based research, such studies will not going to be completed without some sketches (Figure 9). Sometime, illustrative drawings can be more effective than the writings in delivering such analyses. Though, for the current stage, the researchers had felt comfortable with their research design, an in-depth approach, probably an alternative observational strategy; modeled by Hassan (2010), could be developed for their next academic writing.

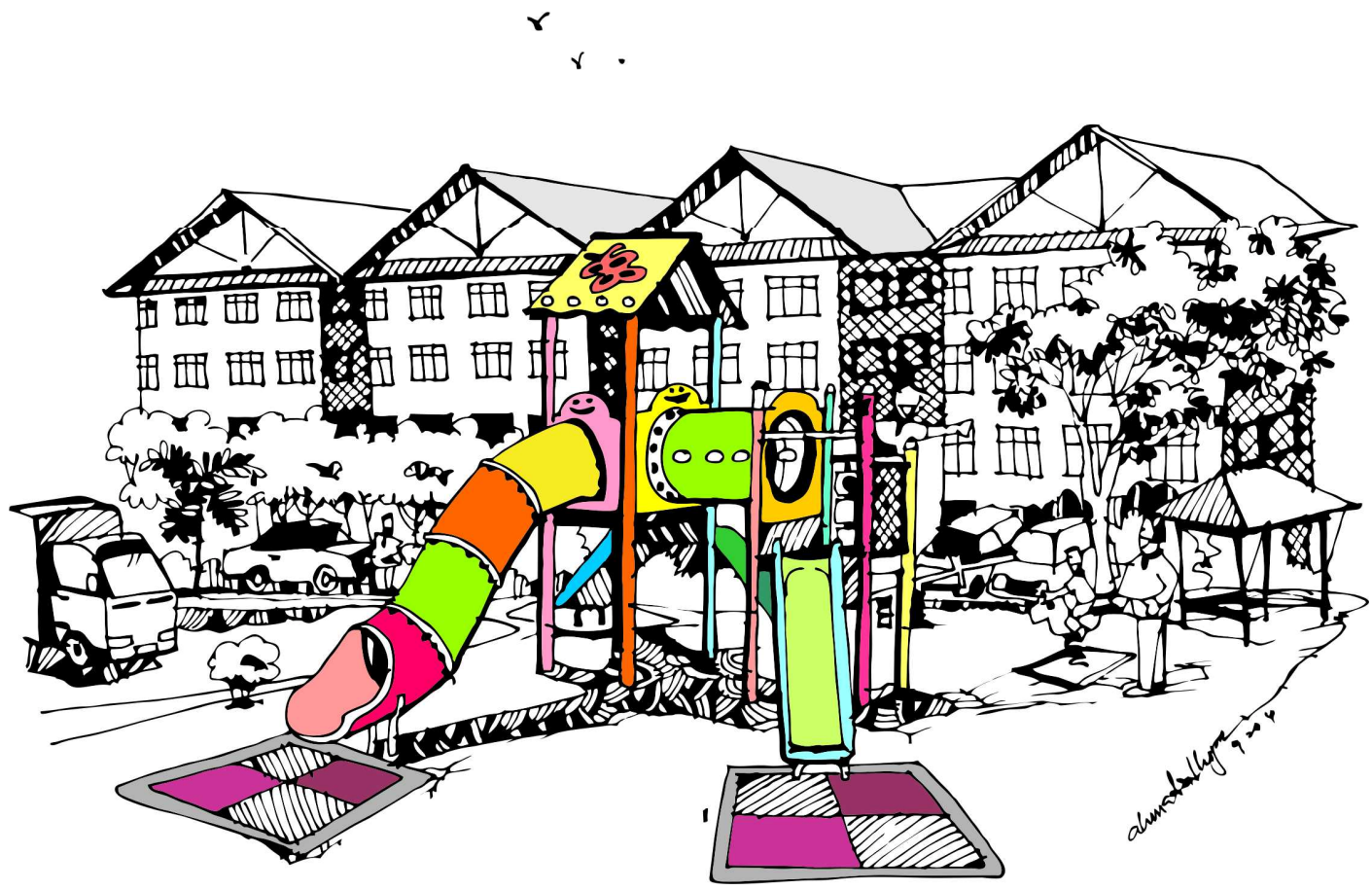

Figure 9. An observational sketch by the researcher of an apartment's playground at Suka Menanti, Alor Setar

Qualitatively, data were derived from observations, interviews and content analyses. Temporarily, evaluation and assessment were yet to focus on any particular scope. For example, a study of playground safety in Putrajaya, which would be a good topic in specific, but that, could only be done providing an ample time. Instead, the study 
was dispersed in a few cities to get an overall picture instantly. In this pioneering project, the assessment of children's playgrounds in Malaysia focused on the perspective of architectural design safety. Architecturally, the project scales will be expanded from time to time in order to seek for new ideas, solutions and innovations. As a token of reward, safer and better designs are hugely anticipated for the future of Malaysian children's playgrounds, which the aims will be a part of the project's milestone; to conduct an ultimate research pertaining to playground safety and design in Malaysia.

\section{Conclusion}

A children's playground is a positive presentation for any housing areas. It will be a good focal point, as well as to enhance the 'leisure ambience' for the whole residential area (Figure 9). The researchers had observed many new playgrounds; most of them were left forgotten soon after their projects were completed. That was how the story of failure had begun. Those playgrounds were assumed to be the entities of maintenance-free.

Even though, this study was conducted only in certain regions, but the sampling population could be well reflected similar situations for the whole nation. Children's playgrounds in Malaysia were heading for a crisis caused by inadequate maintenance practice and the lack of safety awareness. Most of our playgrounds will struggle to comply with the safety checklists recommend for the fall surfacing, drainage, general hazards and durability of equipment.

A case in Putrajaya for instance, a supremely utmost city of Malaysia; everything was provided to the level best. Their playgrounds were superbly impressive, unique and perhaps the best in the country. However, if an investigation was to be conducted in close proximity; many things won't be right and safe. Sharp edges, protruding bolts and nuts were everywhere, especially at the equipment's undersides and on the replaced parts. Even though the PJC had managed to conduct a regular maintenance check for Putrajaya's playgrounds, much better than the local authorities in other cities, their works, however, were not up to the specifications of any international playground standards.

Poor maintenance practice will invite more problems towards the playground equipment. Those playgrounds used to be the places of leisure, nevertheless, because of being badly maintained or haven't been maintained at all, they would still continue to endure, but now, as the failure playgrounds. Malaysians were good at building something for the records, but did not care a lot. This stigma has to be changed; to see the rise of our playgrounds again!

\section{Acknowledgments}

The authors would like to express appreciation for the financial support under Research University Grant (Account Number 1001/PPBGN/816237 by Universiti Sains Malaysia.

\section{References}

Aaron, D., \& Winawer, B. (1965). Child's Play. Harper \& Row.

Allen, E. M., Hill, A. L., Tranter, E., \& Sheehan, K. M. (2012). Playground Safety and Quality in Chicago. Official Journal of the American Academy of Pediatrics 2013, 131, 233.

Amouzegar, Z., Naeini, H. S., \& Jafari, R. (2009). Design principle of playgrounds' equipment and spaces for children: An interaction education approach. Procedia Social and Behavioral Sciences, 2, 1968-1971. http://dx.doi.org/10.1016/j.sbspro.2010.03.265

Bachvarov, I., Balle, H., Berlinski, D., Frankowska, J., Kurzyna-Warczakoska, A., van Leent, J., ..., Yearley, D. (2008). Playground Handbook for Inspectors: Safe Play on the Playground! Improving the safety of the playground equipment by market surveillance authorities' cooperation and raising the awareness of consumers. Office of Competition and Consumer Protection. Retrieved December 12, 2013, from http://www.prosafe.org/read_write/file/Playground_HB_for_Inspectors-21_03_1-\%20IoZl.pdf

Bernardo, L. M., Gardner, M. J., \& Seibel, K. (2001). Playground injuries in children: A review and Pennsylvania trauma center experience. Journal of the Society of Pediatric Nurses, 6(1), 11-20. http://dx.doi.org/10.1111/j.1744-6155.2001.tb00114.x

Beugels, L. J. M. (1993). Reporting the Inspection Results: A Survey in the Netherlands-VWA. The Netherlands; Inspectorate for Health Protection's-Hertogenbosch; Rapport SH9303.

Bhattacharya, S., Cummings, H., Gilmore, J., Karr, A., Lee, C., Olson, J., ..., Yokel, N. (2003). Universal Playgrounds: Integrating All Children through Play. Gemstone Universal Playgrounds Team; Thesis submitted in partial fulfillment of the requirements of the Gemstone Program, University of Maryland, 
2003.

Bond, M. T., \& Peck, M. G. (1993). The risk of childhood injury on Boston's playground equipment and surfaces. American Journal of Public Health, 83(5), 731. http://dx.doi.org/10.2105/AJPH.83.5.731

Buck, D. J. (1988). Safe on Playgrounds? The Nature and Causes of Children's Playground Accidents and Opportunities for Prevention. Public Health, 102, 603-611. http://dx.doi.org/10.1016/S0033-3506(88) 80031-3

Chalmers, D. J., \& Langley, J. D. (1990). Epidemiology of playground equipment injuries resulting in hospitalization. J. Paediatr Child Health, 26, 329-334. http://dx.doi.org/10.1111/j.1440-1754.1990. tb02446.x

Chalmers, D. J., Marshall, S. W., Langley, J. D., Evans, M. J., Brunton, C. R., Kelly, A. M. \& Pickering, A. F. (1996). Height and surfacing as risk factors for injury in falls from playground equipment: A case-control study. Injury Prevention, 2, 98-104. http://dx.doi.org/10.1136/ip.2.2.98

Deconinck, J. (2009). Playground Safety in Belgium. Retrieved May 25, 2014, from http://www.playgrounds. uokik.gov.pl/download/en_playground_safety_in_belgium.pdf

Dewi, S. P. (2010). How Does The Playground Role in Realizing Children-Friendly-City? Asia Pacific International Conference on Environment-Behavior Studies, Grand Margherita Hotel, Kuching, Sarawak, Malaysia, 7-9 December 2010. Procedia-Social and Behavioral Sciences, 38, 224-233.

Fiissel, D., Pattison, G., \& Howard, A. W. (2005). Severity of playground fractures: Play equipment versus standing height falls. Injury Prevention, 11, 337-339. http://dx.doi.org/10.1136/ip.2005.009167

Gordon, D. M. (1981). Toward a safer playground. Day Care Council of America, 46-53.

Hassan, A. S. (2010). Islam Came to South East Asia From China: Evidence from Traditional Chinese Roof Design in Kampung Laut's Old Mosque, Malaysia. Canadian Social Science, 6(5), 1-15.

Hassan, A. S., Emalgalfta, A., \& Ku Hassan, K. A. (2010). Development of Successful Resort Design with Vernacular Style in Langkawi, Malaysia. Asian Culture and History, 2(1), 1-13. http://dx.doi.org/10.5539 /ach.v2n1p85

Howard, A. W., Macarthur, C., Rothman, L., Willan, A., \& Macpherson, A. K. (2009). School Playground Surfacing and Arm Fractures in Children: A Cluster Randomized Trial Comparing Sand to Wood Chip Surfaces. PLoS Med., 6(12), e1000195. http://dx.doi.org/10.1371/journal.pmed.1000195

Hurlock, E. B. (1978). Child Development. New York: Mc Graw-Hill, Inc.

Kamel, D. K. E., \& Khodeir, L. M. (2012). A strategy for selecting safe and low maintenance floorings in early childhood centers outdoors (Cairo, Egypt). An in Shams Engineering Journal, 4, 939-950. http://dx.doi.org /10.1016/j.asej.2012.12.004

Kutska, K. S. (2007). Regular Playground Maintenance and Inspection. The reasons it matters. Today's Playground, 48-54.

Laforest, S., Robitaille, Y., Lesage, D., \& Dorval, D. (2001). Surface Characteristics, Equipment Height, and the Occurrence and Severity of Playground Injuries. Injury Prevention, 7, 35-40. http://dx.doi.org/10.1136/ip. 7.1 .35

Leung, K. W. P., \& Mahadev, A. (2011). The cost of sustaining playground related extremity fractures in Singapore. J. Care Injured, 42, 352-355. Injury, Int. http://dx.doi.org/10.1016/j.injury.2010.05.024

Mack, M. G., Hudson, S., \& Thompson, D. (1997). A descriptive analysis of children's playground injuries in the United States 1990-2004. Injury Prevention, 3, 100-103. http://dx.doi.org/10.1136/ip.3.2.100

Mackay, M. (2003). Playground Injuries: Recent attempt to begin to address what we don't know. Injury Prevention, 9, 194-196. http://dx.doi.org/10.1136/ip.9.3.194

Macpherson, A. K., Jones, J., Rothman, L., Macarthur, C., \& Howard, A. W. (2010). Safety standards and socioeconomic disparities in school playground injuries: A retrospective cohort study. BMC Public Health, 10, 542. http://dx.doi.org/10.1186/1471-2458-10-542

Malaysian Standard 966. (2001). Playground Equipment Part 1, 2 \& 3. Department of Standards Malaysia.

Mani, M., Hosseini, S. M., \& Abdullah, A. (2012). Property values and safety improvement strategy of playground. Business Strategy Series, 13(1), 47-53. http://dx.doi.org/10.1108/17515631211194625 
Md Zain, N., \& Mokhtar, S. A. I. (2012). Safety on the Playgrounds. Retrieved May 20, 2014, from http://www.myhealth.gov.my/index.php/my/bayikanak-kanak/kecederaan-kemalangan-a-keracunan/keselam atan-di-taman-permainan

Minuzzo, B., Rowan, H., \& Young, L. (2009). Child Safety Handbook Edition 5: A guide to injury prevention for parents of 6-12 year olds. Compiled by The Royal Children's Hospital Safety Centre, Melbourne. Retrieved May 24, 2014, from http://www.rch.org.au/uploadedFiles/Main/Content/safetycentre/ChildSafetyHandbook. pdf

Mitchell, R., Sherker, S., Cavanagh, M., \& Eager, D. (2007). Falls from playground equipment: Will the new Australian playground safety standard make a difference and how will we tell? Health Promotion Journal of Australia, 18, 98-104.

Moore, R., Frumkin, H., Geller, R., Rubin, L., \& Nodvin, J. (2006). Playgrounds: A 150-Year-Old Model. Safe and Healthy School Environments, 8, 86-103. http://dx.doi.org/10.1093/acprof:oso/9780195179477. 003.0008

Morrongiello, B. A., \& Matheis, S. (2007). Addressing the Issue of Falls off Playground Equipment: An Empirically-Based Intervention to Reduce Fall-Risk Behaviors on Playgrounds. Journal of Pediatric Psychology, 32, 819-830. http://dx.doi.org/10.1093/jpepsy/jsm029

Mott, A., Evans, R., Rolfe, K., Potter, D., Kemp, K. W., \& Sibert, J. R. (1994). Pattern of injuries to children on public playgrounds. Arch Dis Child, 71(4), 300-328. http://dx.doi.org/10.1136/adc.71.4.328

Mott, A., Rolfe, K., James, R., Evans, R., Kemp, A., Dunstan, F., .., Sibert, J. R. (1997). Safety of surfaces and equipment for children in playgrounds. The Lancet, 349, 1874-1876. http://dx.doi.org/10.1016/S0140-6736 (96)10343-3

National Program for Playground Safety. (2006). America's Playgrounds Safety Report Card. Retrieved February 12, 2014, from http://www.playgroundsafety.org

Nixon, J. W., Acton, C. H. C., Wallis, B., Ballesteros, M. F., \& Battistutta, D. (2003). Injury and frequency of use of playground equipment in public schools and parks in Brisbane, Australia. Injury Prevention, 9(3), 210-213. http://dx.doi.org/10.1136/ip.9.3.210

Phelan, K., Khoury, J., Kalkwarf, H., \& Lamphear, B. (2001). Trends and patterns of playground injuries in United States. Ambulatory Pediatrics, 1, 227-233. http://dx.doi.org/10.1367/1539-4409(2001)001<0227: TAPOPI $>2.0 . \mathrm{CO} ; 2$

Piaget, J. (1962). Play, dreams and imitation in childhood. London: Routledge \& Kegan Paul.

Roseveare, C. A., Brown, J. M., Barclay-McIntosh, J. M., \& Chalmers, D. J. (1999). An intervention to reduce playground equipment Hazards. Injury Prevention, 5, 124-128. http://dx.doi.org/10.1136/ip.5.2.124

Shier, H. (1984). Adventure Playgrounds: An Introduction (pp. 1-24). Retrieved May 27, 2014, from http://www.londonplay.org.uk/resources/0000/1190/1984_Intro_to_APs_Harry_Shier.pdf

Smoyer-Tomic, K. E., Hewko, J. N., \& Hodgson, M. J. (2004). Spatial accessibility and equity of playgrounds in Edmonton, Canada. Canadian Geographer, 48(3), 287-302. http://dx.doi.org/10.1111/j.0008-3658.2004. 00061.x

Stoecklin, V. L. (2000). Creating Playgrounds Kids Love: White Hutchinson Leisure and Learning Group. Retrieved April 15, 2014, from http://www.whitehutchinson.com/articles/playgroundskidslove.html

Sutterby, J. A., \& Thornton, C. D. (2005). It Doesn't Just Happen! Essential Contributions from Playgrounds. YC Young Children, 60(3), 26-33.

Swartz, M. K. (1992). Playground Safety. Journal of Pediatric Health Care, 6(3), 161-162. http://dx.doi.org/10. 1016/0891-5245(92)90149-X

Tinsworth, D. K., \& McDonald, J. E. (2001). Special study: Injuries and deaths associated with children's playground equipment. Directorate for Epidemiology; U.S. Consumer Product Safety Commission; Washington, D.C. 20207.

U.S. Consumer Product Safety Commission. (2010). Handbook for Public Playground Safety. Publication Number 325. Washington, DC: U.S. Consumer Product Safety Commission.

Uskun, E., Kisioglu, A. N., Altay, T., Cikinlar, R., \& Kocakaya, A. (2008). Assessment of the current status of playground safety in the Midwestern region of Turkey: An effort to provide a safe environment for children. 
The Turkish Journal of Pediatrics, 50, 559-565.

Van Weperen, \& Rogmans, W. H. J. (1991). An overall approach to the safety of playgrounds. Safety Science, 14, 103-108. http://dx.doi.org/10.1016/0925-7535(91)90004-6

Wade, B. (2002). Playground Design: It's more than child's play. American City and County, 114, 24-26.

Wheway, R. (2012). Grass and impact absorbing surfacing in children's playgrounds. Children's Play Advisory Service. Retrieved April 13, 2014, from http://www.childrensplayadvisoryservice.org.uk/pdf_files/ Publications/Surfacing_in_playgrounds.pdf

White, N. B. (2012). Designing Child's Play Takes Serious Planning. Retrieved May 2, 2014, from http://www.thepublicmanager.org

Zeece, P. D., \& Graul, S. K. (1993). Playgrounds for Play: Sound, Safe, and Sensational. Day Care and Early Education, 23-27. http://dx.doi.org/10.1007/BF01617784

\section{Copyrights}

Copyright for this article is retained by the author(s), with first publication rights granted to the journal.

This is an open-access article distributed under the terms and conditions of the Creative Commons Attribution license (http://creativecommons.org/licenses/by/3.0/). 